\title{
Study on the Effect of LHA on Feeding and its Mechanism
}

\section{WANG Zhong-xiang ${ }^{1,2}$, WANG Mi1 ${ }^{1}$, WANG Qian ${ }^{1}$, SUN Xiang-rong ${ }^{1}$, XU Luo'}

\author{
${ }^{1}$ Qingdao University, Qingdao, Shandong, 266021, China \\ ${ }^{2}$ Zaozhuang Municipal Hospital, Zaozhuang, Shandong, 277000, China
}

\begin{abstract}
Objective: To study the effect of lateral hypothalamic area on feeding and its specific mechanism. Methods: Intraventricular catheterization was used in rats,GLP-1 receptor agonist Ex4 or GLP-1 receptor antagonist Ex9 were injected into the lateral hypothalamic area (LHA) of rats, and the effects of food intake, water intake, body weight, kaolin intake and high-carbonhydrate diet were observed. Results: Immunohistochemical experiments showed the presence of GLP-1 receptor LHA in rats; When GLP-1 receptor was excited, the $1 \mathrm{~h}$ and $24 \mathrm{~h}$ food intake of rats decreased, and the body weight decreased, and there was no significant change in the kaolin intake in rats; When GLP-1 receptor was blocked, there was no significant change in $24 \mathrm{~h}$ food intake but weight gain in rats; When GLP-1 receptor was excited, high-carbonhydrate diet significantly reduced but there was no significant change in water intake; When GLP-1 receptor was blocked, high-carbonhydrate diet significantly increased but there was no significant change in water intake. Conclusion: GLP-1 receptor can be involved in the regulation of feeding behavior, and the signal may be related to the hedonicproperties of food.
\end{abstract}

Keywords: Food intake; GLP-1; LHA

\section{Introduction}

Obesity and related metabolic diseases are spreading globally, and little is known about the effective treatment of obesity. Feeding and body weight are mainly regulated by the central nervous system. Therefore, studies on the relevant mechanisms of the central nervous system are essential for the treatment of obesity. Glucagon-like peptide 1 (GLP-1) is a peptide that has been discovered in recent years and has an effect on feeding. It is mainly produced by the peripheral peri-gastric L cells and the brain. In the brain, glucagon-like peptide 1 (GLP-1) is mainly produced by solitary tract nucleus (NTS) neurons ${ }^{[1]}$. Nutritional uptake, gastric dilatation, cholecystokinin, and vagal afferent stimulation can activate these Cells and participate in the regulation of feeding ${ }^{[2]}$. Intracerebroventricular injection of GLP-1 inhibits feeding, and intracerebroventricular injection of the GLP-1 receptor (GLP-1R) antagonist Exendin9 (Ex9) or NTS GLP-1 gene knockdown increases rat food intake $^{[3]}$. Studies have shown that central GLP-1 is crucial to the physiological regulation of energy balance. NTS GLP-1 neurons can be projected to the entire brain ${ }^{[4]}$. However, research on the GLP-1R signal has mainly focused on the hypothalamic nuclei and the $\mathrm{NTS}^{[5]}$. Current research shows that the ventral tegmental area (VTA) and nucleus accumbens GLP-1R in the midbrain can influence the feeding and reward system $^{[6]}$, suggesting that GLP-1 plays an important physiological role in regulation of food intake and motivational behavior.

The hypothalamic lateral area (LHA) is known as the "satisfaction center" and has a driving effect on the intake of water in rats. Previous studies have shown that LHA bilateral damage can cause rats to lose eating $^{[7]}$. In contrast, stimulating LHA induces food intake and may even promote food intake in satiety rats $^{[8]}$. LHA also plays an important role in energy balance and hedonic behavior control. In addition, there is a two-way fiber connection between the LHA and multiple nuclei, such as the lateral septal nucleus ${ }^{[9]}$. LHA is innervated by the hindbrain GLP-1 neurons, and GLP-1 receptor (GLP-1R) is also present in $\mathrm{LHA}^{[10]}$. Recent studies have shown that neurons in the lateral septal nucleus project to VTA and LHA and play a role in cocaine rewards ${ }^{[11]}$.

Currently, GLP-1 analogues are approved by the State for the treatment of type 2 diabetes and obesity ${ }^{[12]}$. Previous studies have suggested that central nervous system injection of GLP-1 or GLP-1R receptor agonist 
Ex4 can reduce food intake and body weight, which is mainly attributable to Activation of hypothalamic and brainstem GLP-1R targets ${ }^{[13]}$. Recent studies have found that GLP-1 signaling is associated with food and drug rewards ${ }^{[14]}$. In addition, previous studies have found that central injections of GLP-1R blockers or GLP-1R knockouts have only a minor effect on the rats' eating or body weight ${ }^{[15]}$. Our influence on the regulation of GLP-1 feeding in LHA is unclear.

Therefore, here we use LHA as a site of action for GLP-1 feeding regulation. Our data studies show that the GLP-1R receptor signal in LHA plays an important physiological role in regulation of feeding, and LHA is important for regulation of central feeding contributors.

\section{Materials and methods \\ 1.1 Animals}

Male Wistar rats, 280-350 g, were purchased from Qingdao Experimental Animal and Animal Experimental Center. The animal room was kept at a constant temperature, and light was circulated day and night from 6:00 to 18:00 (12 hours). The rats were allowed to eat freely and feed on standard diets. All animals followed the "Qingdao University Laboratory Animal Protection and Use Management Method." All experiments were in accordance with the Qingdao Animal Center Standard.

\subsection{Brain catheterization}

Rats were anesthetized with an intraperitoneal injection of $10 \%$ chloral hydrate $(0.3 \mathrm{ml} / 100 \mathrm{~g})$ and placed in a stereotaxic positioner. With reference to the rat brain map, the lateral ventricle $\mathrm{LV}(0.9 \mathrm{~mm}$ posterior, 1.5 $\mathrm{mm}$ lateral, $2.7 \mathrm{~mm}$ deep) and lateral hypothalamic LHA (1.3-2.3 mm posterior 1.5-2.5 mm lateral, depth 8.0-9.0 mm), implanted in stainless steel cannula, polyethylene tubing $(10 \mathrm{~cm})$ connecting cannula and syringe, postoperative recovery for 1 week.

\subsection{Immunohistochemistry Experiment}

Rats were injected with $0.2 \mu \mathrm{g}$ of FAM-labeled GLP-1 agonist Ex4 in the lateral ventricle, and three hours after injection, the rats were anesthetized with $10 \%$ chloral hydrate $(0.3 \mathrm{~mL} / 100 \mathrm{~g})$ intraperitoneally and given $200 \mathrm{~mL} 0.9 \%$. Normal saline was rapidly perfused and then fixed with $200 \mathrm{ml}$ of $4 \%$ paraformaldehyde. The brain was soaked in $4 \%$ paraformaldehyde for 4-6 h, and then stored in 30\% sucrose solution for $2-3$ days at $4{ }^{\circ} \mathrm{C}$. The cryostat was coronally cut into $20 \mu \mathrm{m}$ sections and stored at $4^{\circ} \mathrm{C}$ for GLP-1 receptor staining. The slices were left at room temperature for 1 hour. The PBS solution was washed 3 times. After washing, they were immersed in citric acid buffer for microwave repair. After repair, normal donkey serum was added to block nonspecific antigens. Each brain slice was 30-50 $\mu \mathrm{l}$. Protect from light and incubate at room temperature for $1 \mathrm{~h}$. Pipette primary antibody drop, anti-GLP-1R antibody (polyclonal antibody, 1:500 dilution), the sample with the primary antibody was placed in a wet box, overnight at $4{ }^{\circ} \mathrm{C}$ (light protection operation). The PBS solution was washed 3 times, and then fluorescein Cy5 labeled secondary antibody (donkey anti-rabbit, 1:500 dilution) was added dropwise and incubated at room temperature for $2 \mathrm{~h}$ (protected from light). After the oil seal was quenched, the cells were observed and counted under a fluorescence microscope.

\subsection{Determination of food intake and body weight}

The rats fasted overnight before starting the experiment. On the second day during the day, 30 rats were randomly selected and divided into two groups. Ex4 or Ex9 was injected unilaterally at 17:00 LHA. The first part was normal saline $(\mathrm{n}=6)$ and $0.03 \mu \mathrm{g} / 0.2 \mu \mathrm{l}$ Ex4 $(\mathrm{n}=6)$. ), $0.1 \mu \mathrm{g} / 0.2 \mu \mathrm{l}$ Ex4 $(\mathrm{n}=6)$; Part 2: Saline group $(\mathrm{n}=6), 20 \mu \mathrm{g} / 0.5 \mu \mathrm{l} \operatorname{Ex} 9 \quad(\mathrm{n}=6)$. At 18:00, the rats resumed their diets, and the food intakes of the rats at 1 $\mathrm{h}$ and $24 \mathrm{~h}$ and the body weight changes at $24 \mathrm{~h}$ were recorded.

\subsection{Determination of kaolin consumption}

Seven days before the experiment, rats were free to consume food and kaolin for adaptive training. On the day of the experiment, fasting began at 14:00. At 17:30, rat LHA was injected with physiological saline or 0.1 $\mu \mathrm{g}$ of Ex4. At 18:00, the rats resumed their diets and the rats were continuously recorded for $20 \mathrm{~h}$ of kaolin intake and food intake.

\subsection{Determination of high-sugar diet}

In order to achieve a stable intake and reduce the freshness of food, the rats adapt to intake of high-calorie chocolate balls and sucrose solution six days before the start of the experiment. On the day of the experiment, 54 rats were randomly selected and divided into four sections and unilaterally injected with Ex4 or Ex9 at 17:00 LHA. The first part was saline $(n=6)$ and $0.1 \mu \mathrm{g} / 0.2 \mu \mathrm{l}$ of Ex4 $(\mathrm{n}=6)$. This group provides chocolate balls; Part 2: Saline group $(n=6)$, $0.03 \mu \mathrm{g} / 0.2 \mu \mathrm{l} \operatorname{Ex} 4(\mathrm{n}=6), 0.1 \mu \mathrm{g} / 0.2 \mu \mathrm{Ex} 4(\mathrm{n}=6)$, this group provides sucrose solution Part 3: Saline group $(\mathrm{n}=6), 20 \mu \mathrm{g} / 0.5 \mu \mathrm{l} \operatorname{Ex} 9(\mathrm{n}=6)$, this group provides chocolate balls; Part 4: Saline group $(\mathrm{n}=6), 20 \mu \mathrm{g} / 0.5 \mu \mathrm{l}$ Ex9 $(n=6)$ This group provides sucrose solution. The $2 \mathrm{~h}$ chocolate ball intake and $4 \mathrm{~h}$ sucrose intake were recorded continuously.

\subsection{Statistical Analysis}

SPSS 18.0 software was used for statistical analysis. All data were expressed as $( \pm \mathrm{SD})$. One-way analysis of variance was used to compare the mean of multiple samples. The t-test was used to compare the mean of 
the two groups. $\mathrm{P}<0.05$ was considered statistically significant.

\section{Results}

2.1 Immunohistochemical expression of GLP-1 receptor in LHA

Intracerebroventricular injection of fluorescently labeled Ex4, fluorescence microscopy found that LHA has fluorescent Ex4 labeled neurons (Fig. 1A), on the

same level with GLP-1 receptor antibody fluorescent immunohistochemical staining, the results showed that LHA cytoplasmic GLP The -1 receptor-active neuron (Fig. 1B) and the partially fluorescent Ex4-labeled cells express GLP-1 receptor-stained cells (Fig. 1C). Undecided with non-fluorescently labeled neurons (Fig. 1D). It is suggested that there is GLP-1 receptor in LHA and it has position-specificity.
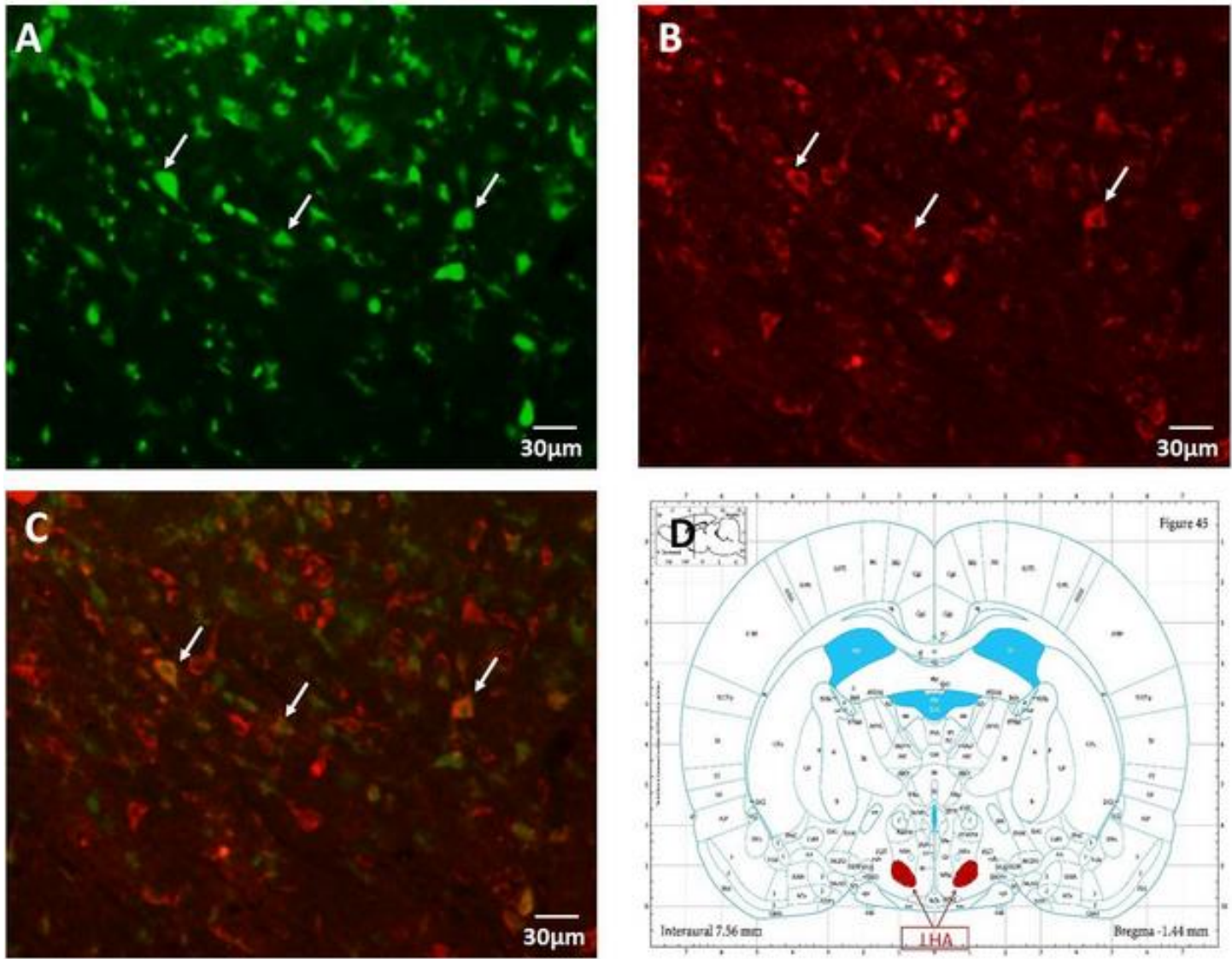

Fig.1 Expression of GLP-1R in LHA

A: Fluoro-Ex4labeled neurons B:neurons in the same area identified by NeuN staining C:merged images of fluoro-Ex4 and NeuN. D: the zonaincerta contained no Ex4 labeling

\subsection{The effect of LHA GLP-1 receptor on food} intake and body weight in rats

Compared with the saline group, LHA injection of $0.03 \mu \mathrm{g}$ Ex4, rats $1 \mathrm{~h}$ food intake reduced ( $\mathrm{p}<0.05$, Fig. 2A), LHA injection of $0.1 \mu \mathrm{g} E x 4$, rats $1 \mathrm{~h}$ food intake was significantly reduced ( $<<0.01$, Fig. $2 A)$. Compared with the saline group, LHA injection of $0.1 \mu \mathrm{g}$ Ex4 significantly reduced the rats' $24 \mathrm{~h}$ food intake $(\mathrm{p}<0.05$, Fig. 2B), LHA injection of $0.03 \mu \mathrm{g}$ Ex 4 didn't effect the rats' $24 \mathrm{~h}$ food intake ( $<<0.05$, Fig. $2 B$ ). Rats were significantly reduced in body weight when injected with $0.1 \mu \mathrm{g}$ of Ex4 to LHA ( $<<0.05$, Fig. $2 \mathrm{C})$. 

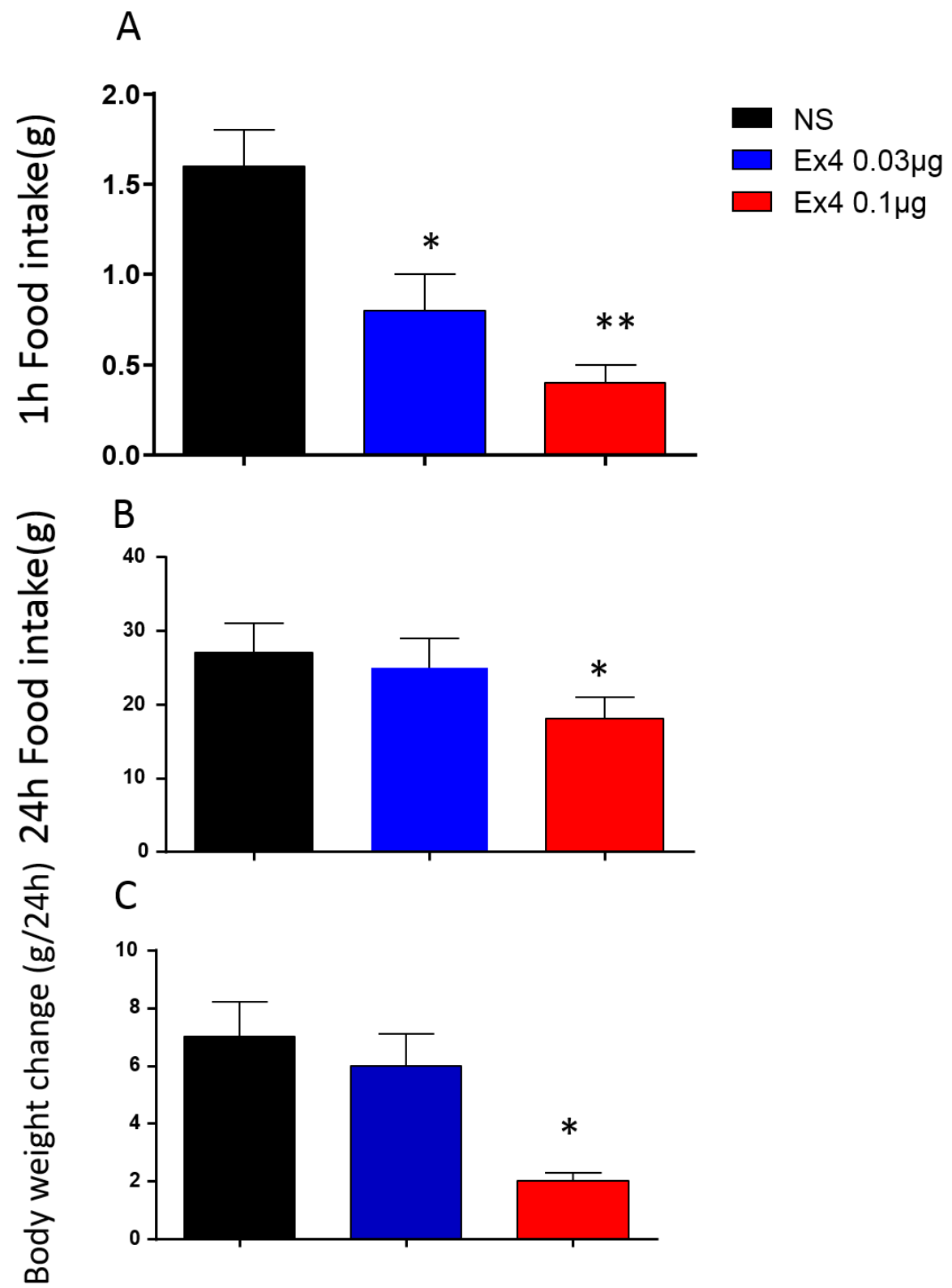

Fig.2 Effect of Ex4 on food intake and body weight in LHA of rats

A: $1 \mathrm{~h}$ food intake B: $24 \mathrm{~h}$ food intake C:Body weight change $* \mathrm{P}<0.05, * * \mathrm{P}<0.01$ vs. NS group

\subsection{The effect of LHA GLP-1 receptor on high} glucose diet in rats

To investigate the effect of GLP-1 receptors on palatability in rats, we recorded rats' intake of high-calorie sweet chocolate balls, non-caloric sweet sucrose solution, and water. Compared with the saline group, LHA injection of Ex4 significantly decreased the intake of chocolate balls at $0.5 \mathrm{~h}, 1 \mathrm{~h}$, and $2 \mathrm{~h}$ in rats $(\mathrm{p}<0.05$, Fig. 3A), and significantly reduced sucrose intake at $4 \mathrm{~h}$ in rats $(\mathrm{p}<0.05)$. Fig. $3 \mathrm{C})$, while there was no significant change in water intake at $4 \mathrm{~h}$ ( $>0.05$, Figure 3B). 


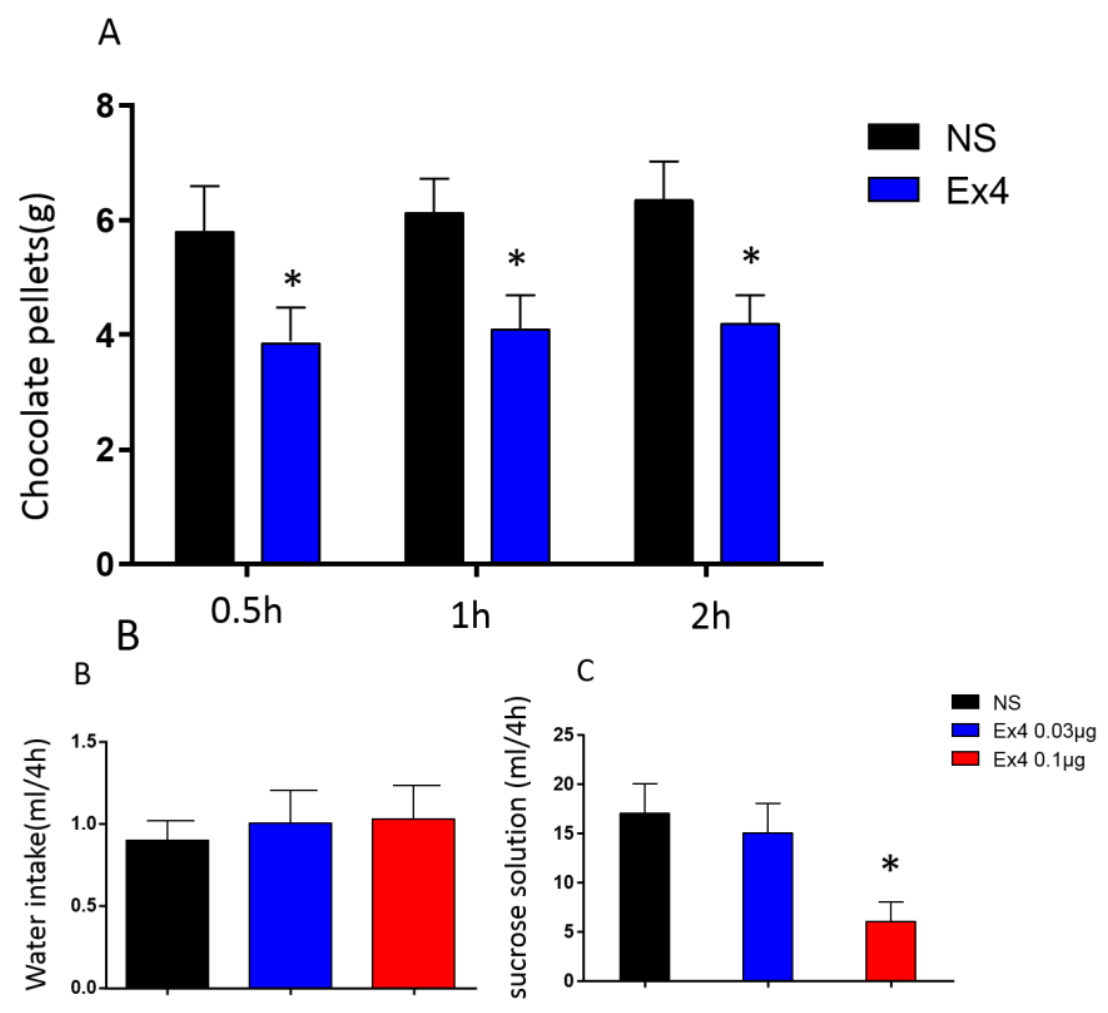

Fig.3 Effect of Ex4 on high-carbonhydrate dietin LHA of rats

A: chocolate pellets B:water intake C: sucrose solution $* \mathrm{P}<0.05$ vs. NS group

\subsection{Effect of Agonist LHA GLP-1 Receptor on Rat} Kaolin intake

To investigate whether the inhibition of Ex4 feeding on rats was caused by vomiting, we recorded $20 \mathrm{~h}$ of kaolin intake in rats. Throughout the experiment, rats had very little kaolin uptake. LHA injection of Ex4 showed no significant changes in the intake of kaolin compared with the saline group ( $\mathrm{P}>0.05$, Fig. 3).

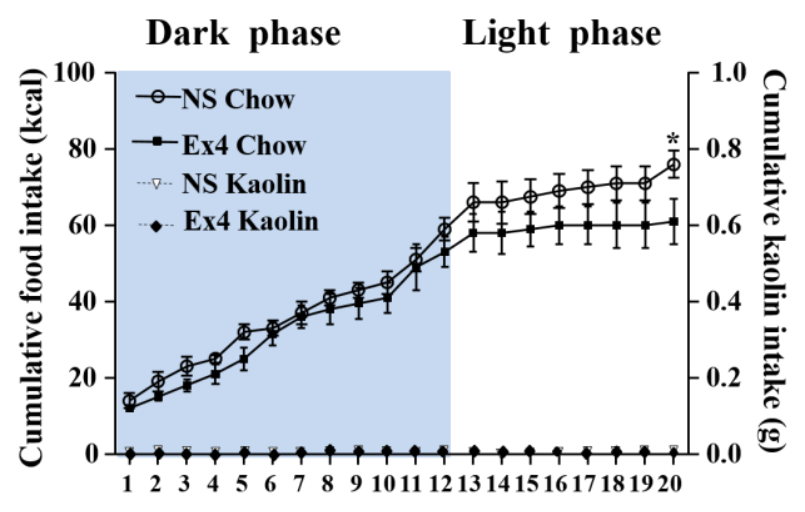

Fig.4 Effect of Ex4 on kaolin and chow intake in LHA of rats

$* \mathrm{P}<0.05$ vs. NS group 
2.5 Effect of blocking LHA GLP-1 receptor on food intake and body weight in rats

Compared with the saline group, the LHA injection of Ex9 had no change in the first hour of food intake $(\mathrm{P}>0.05$, Fig. 5A), and the second and third hour food intake was significantly increased $(\mathrm{P}<0.05$, Fig. 5A). There was no significant change in the 24-hour food intake in rats $(\mathrm{P}>0.05$, Fig. $5 \mathrm{~B})$, whereas there was a significant increase in 24-hour body weight in rats $(\mathrm{P}<$ 0.05, Fig. 5C).
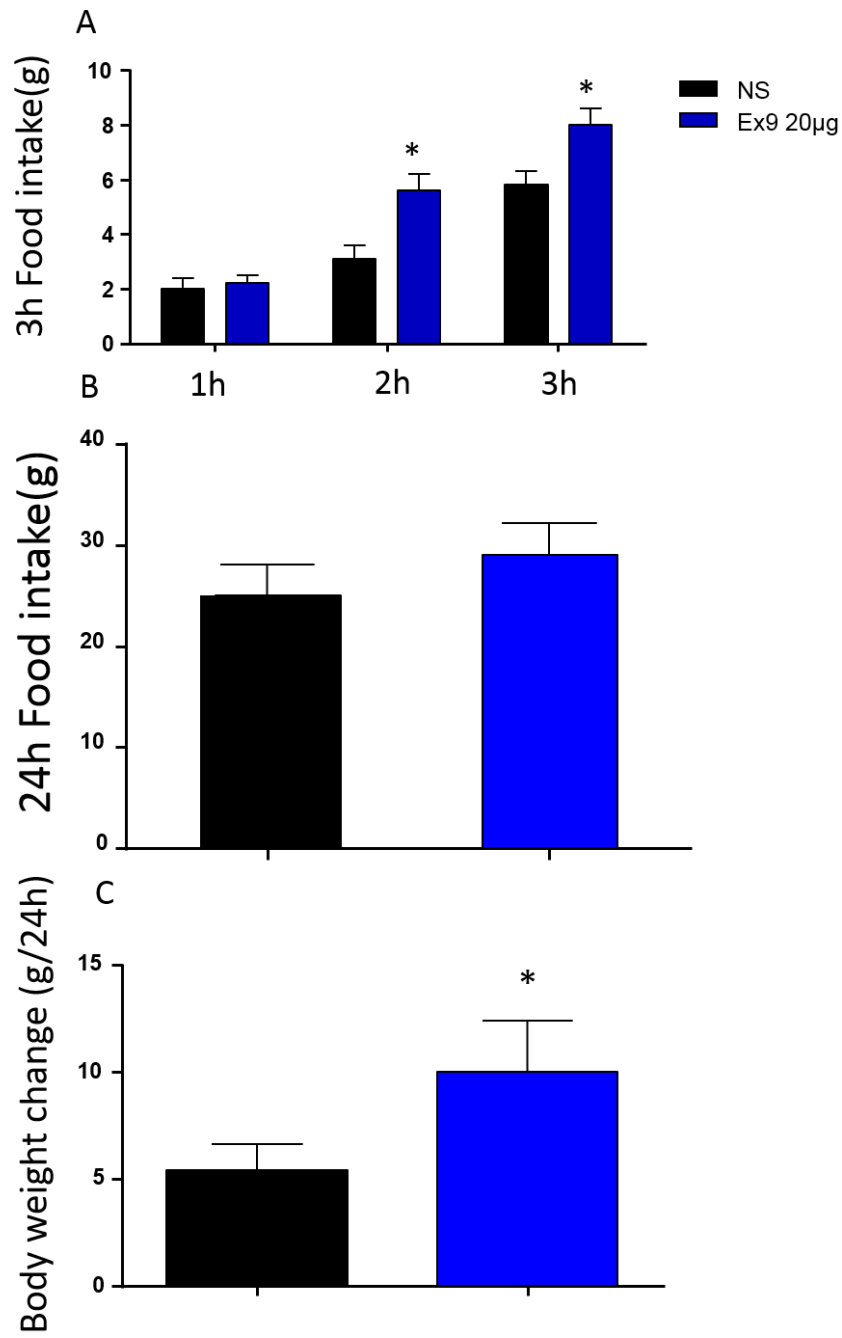

Fig.5 Effect of Ex9 on food intake and body weightin LHA of rats

A: 3 h food intake B:24h food intake C:Body weight change

$* \mathrm{P}<0.05$ vs. NS group

\subsection{Effect of Blocking LHA GLP-1 Receptor on} Rats' High-sugar Diet

Compared with saline group, LHA injection of Ex9 significantly increased the intake of chocolate balls at 1 $\mathrm{h}$ and $2 \mathrm{~h}$ in rats $(\mathrm{p}<0.05$, Fig. $6 \mathrm{~A})$, and the rat sucrose solution intake increased significantly at $4 \mathrm{~h}(\mathrm{p}<0.05$, Fig. 6C). ), but there was no significant change in water intake at $4 \mathrm{~h}(\mathrm{p}>0.05$, Fig. 6B). 


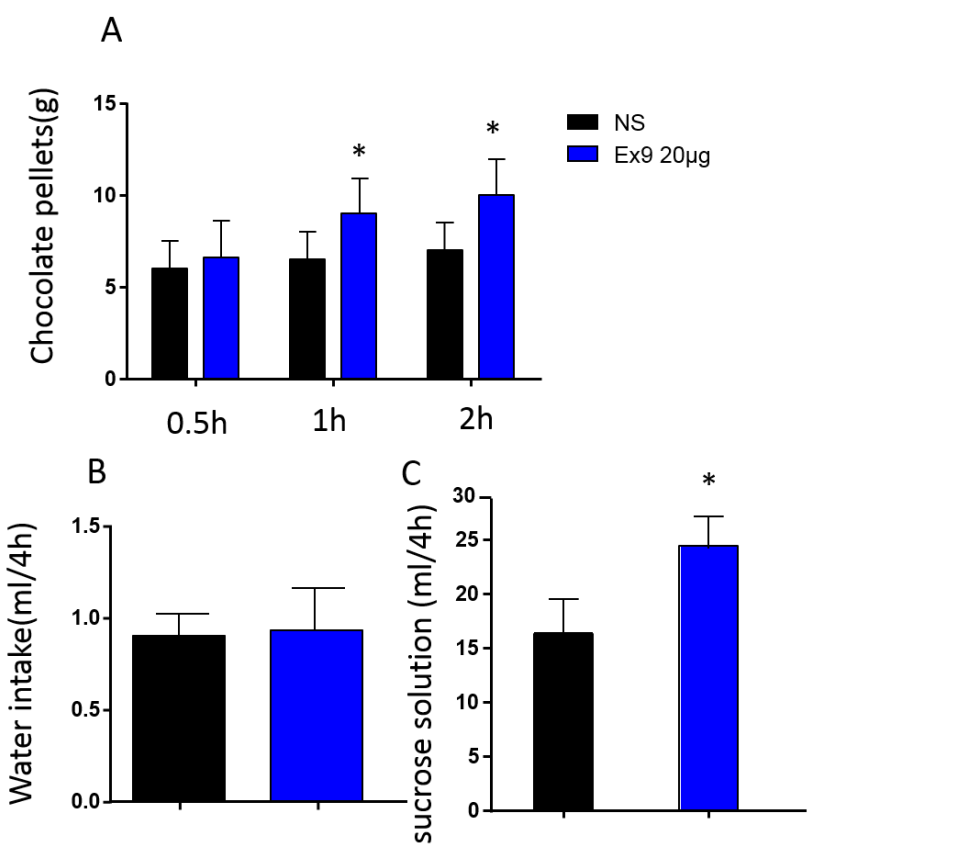

Fig.6 Effect of Ex9 on high-carbonhydrate dietin LHA of rats

A: chocolate pellets B:water intake $C$ : sucrose solution $* \mathrm{P}<0.05$ vs. NS group

\section{Discussion}

With the development of cell and molecular biology, the secret veil of incretin has been gradually unveiled. Research confirms that incretin is an intestinal hormone in the human body. After eating, the hormone can promote Insulin secretion exerts a glucose concentration-dependent hypoglycemic effect. Incretin mainly consists of GLP-1 and glucose-dependent insulin releasing peptide (GIP), of which GLP-1 plays a more important role in the development of type 2 diabetes. The study of GLP-1 may be of diabetes. Treatment and prevention provide targeted strategies.

GLP-1 is expressed by the proglucagon gene and the major glucagon gene expression product is glucagon in pancreatic islet $\alpha$ cells, while prohormone converting enzyme (PC1) is present in $\mathrm{L}$ cells of the intestinal mucosa. Proglucagon is cut into its carboxy-terminal peptide sequence, GLP-1. There are two biologically active forms of GLP-1, GLP-1 (7-37) and GLP-1 (7-36) amides, which have only one amino acid sequence and GLP-1 has approximately $80 \%$ of circulating activity. From GLP-1 (7-36) amide. GLP-1 is produced through a variety of ways to reduce weight, including inhibition of gastrointestinal motility and secretion of gastric juice, suppress appetite and ingestion, and delay gastric emptying. In addition, GLP-1 can also act on the central nervous system (especially the hypothalamus), so that the body produces a sense of fullness and decreased appetite. In addition, GLP-1 also has many other biological characteristics and functions. For example, GLP-1 may exert lipid-lowering and antihypertensive effects, thus exerting a protective effect on the cardiovascular system; it may also act on central reinforcement learning. And memory function to protect nerves.

In our experiment, we used the fluorescently labeled GLP-1 receptor agonist Ex4 to inject into the lateral ventricle (LV) of the rat. We found that the GLP-1 receptor was present in the rat LHA, whereas GLP-1 was not found in the indeterminate band near the LHA. 1 Receptors, indicating that GLP-1 receptors have location-specificity, although they are widespread in the brain. Our experimental data demonstrate that the GLP-1 receptor in LHA plays an important role in the feeding behavior of rats. Clinical studies have demonstrated that subcutaneous injection of GLP-1 increases postprandial satiety and reduces the average dietary intake of each meal by $15 \%$. In our experiment, 
LHA injection of the GLP-1 receptor agonist Ex4 significantly reduced food intake, high calorie chocolate balls, and calorie-free sucrose solution intake in rats, suggesting that the GLP-1 receptor signal in LHA It may be possible to inhibit feeding by inhibiting the desire for palatability and high calorie in rats. Interestingly, we found that activation of the GLP-1 receptor has no effect on water intake in rats. However, the LHA-injected GLP-1 receptor blocker Ex9 has a very modest effect on the feeding of rats, which is similar to previous experimental studies ${ }^{[15]}$, but the rats have high-calorie chocolate balls and a calorie-free sucrose solution. Imports increased significantly. These experimental data indicate that the GLP-1 receptor signal in LHA may be related to calorie density, taste, and hedonic properties of food. Palatability and caloric values may contribute to the activation of the dopamine system in LHA. Previous studies have shown that LHA microinjection of GABAA receptor agonists can cause heral reactions to increase oral sucrose content ${ }^{[16]}$. Overall, our findings indicate that endogenous GLP-1 receptors in the agonizing LHA play an important role in limiting food intake, which may be related to the activation of dopamine. Although previous studies have documented the presence of GLP-1 nerve fibers and receptors, this is the first time that GLP-1 has been shown to function in feeding ${ }^{[17]}$.

Previous studies have shown that GLP-1 can cause changes in visceral disease and taste in rodents after agonism $^{[18]}$. In humans, nausea is the most common side effect. Clinical trials have shown that nausea can be caused by taking duraphinide and benaglutide. However, injection of Ex4 into the ventral tegmental area (VTA), nucleus accumbens, and parahippocampus parabrachial nucleus inhibited feeding, but there was no evidence of nausea ${ }^{[19]}$. Here, we found that intra-LHA injection of Ex4 inhibited feeding and did not induce kaolin uptake, suggesting that the inhibitory effect of GLP-1 receptor uptake in LHA is not nausea.

We have determined that central GLP-1 plays a role in the regulation of feeding behavior, but the specific brain regions that regulate GLP-1 receptor feeding and the mechanisms of action of these receptors are not fully elucidated. Previous experimental studies have shown that GLP-1 receptor subpopulations in different brain regions and even different subregions of the same brain region may have different effects on rat behavior. In some brain regions, GLP-1 receptors can affect glucose homeostasis and produce taste aversion without affecting food intake. Combined with previous studies, we have found that GLP-1 receptors throughout the central nervous system regulate feeding behavior and energy balance through different mechanisms.
Collectively, these data confirm that LHA plays a role in the regulation of physiological feeding behavior. Traditionally, we do not think that LHA plays a role in homeostatic regulation of feeding, but here we find that activation of the GLP-1 receptor in LHA influences feeding, and activation of endogenous GLP-1 receptors in LHA can be Limit intake of high sugar diets. LHA has extensive fiber connections with other areas of the brain associated with feeding, such as the arcuate nucleus and the lateral septum. Therefore, LHA has many efferent pathways that mediate feeding. The nerve fiber endings of LHA cells are mainly GABAergic neurons. Therefore, we speculate that LHA may suppress the projection of feeding neurons and eventually lead to suppression of feeding behavior. The interaction between various neurotransmitters and neuropeptides such as GLP-1, CRH, ghrelin, and GABA can affect feeding behavior, the diversity of neuronal projections to LHA, and the expression of LHA receptors increase this possibility. Future studies will need further elucidation of neural circuit-mediated feeding regulation in LHA.

\section{References}

1. Cork SC, Richards JE, Holt MK, et al. Distribution and characterisation of Glucagon-like peptide-1 receptor expressing cells in the mouse brain[J]. MolMetab, 2015, 4(10):718-731

2. Skibicka KP. The central GLP-1: implications for food and drug reward[J].Front Neurosci, 2013, 7: 181-189

3. Barrera JG, Jones KR, Herman JP, et al. Hyperphagia and increased fat accumulation in two models of chronicCNS glucagon-like peptide-1 loss of function[J]. J Neurosci,2011, 31: 3904-3913

4. Rinaman L. Ascending projections from the caudal visceral nucleus of the solitary tract to brain regions involved in food intake and energyexpenditure[J]. Brain Res,2010, 1350: 18-34

5. Liu J, Conde K, Zhang P, et al. Enhanced AMPA Receptor Trafficking Mediates the Anorexigenic Effect of Endogenous Glucagon-like Peptide-1 in the Paraventricular Hypothalamus[J].Neuron, 2017, 96(4):897-909

6. Alhadeff AL, Rupprecht LE, Hayes MR. GLP-1 neurons in the nucleusof the solitary tract project directly to the ventral tegmental area andnucleus accumbens to control for food intake[J]. Endocrinology, 2012, 153: 647-658

7. Matsuo R, Kobashi M, Mitoh Y, et al. Role of the lateral hypothalamus in submandibular salivary secretion during feeding in rats. [J]. Brain Res, 2015, 1596: 99-107

8. Talakoub O, Paiva RR, Milosevic $M$, et al.Lateral hypothalamic activity indicates hunger and satiety states in humans[J].Ann ClinTransINeurol, 2017, 4(12):897-901

9. Risold PY, Swanson LW. Connections of the rat lateral septal complex[J].Brain Res Brain Res Rev, 2017, 24: 115-195

10. Merchenthaler I, Lane M, Shughrue P. Distribution of pre-pro-glucagon andglucagon-like peptide-1 receptor messenger RNAs in the rat central nervous system[J]. J Comp Neurol, 1999, 403: 261-280

11. Luo AH, Tahsili-Fahadan $\mathrm{P}$, Wise a $\mathrm{R}$, et al.Linking context with reward: a functional circuit from hippocampal CA3to ventral tegmental area[J]. Science, 2011, 333: 353-357

12. Iepsen EW, Torekov SS, Holst JJ. Liraglutide for type 2 diabetes and obesity: a2015 update[J]. Expert Rev 
CardiovascTher, 2015, 13: 753-767

13. Hayes MR. Neuronal and intracellular signaling pathways mediating GLP-1 energybalance and glycemic effects[J]. PhysiolBehav, 2012, 106: 413-416

14. Skibicka KP. The central GLP-1: implications for food and drug reward[J]. FrontNeurosci,2013, 7: 181

15. Finan B, Yang B, Ottaway N, et al. Targetedestrogen delivery reverses the metabolic syndrome[J]. Nat Med, 2012, 18: 1847-1856

16. SöderpalmAH,Berridge KC. The hedonic impact and intake of foodare increased by midazolam microinjection in the parabrachialnucleus[J]. Brain Res, 2000, 877(2): 288-297

17. Göke R, Larsen PJ, Mikkelsen JD, Sheikh SP. Distribution of GLP-1binding sites in the rat brain: Evidence that exendin-4 is a ligand of brainGLP-1 binding sites[J]. Eur J Neurosci, 1995, 7: 2294-2300

18. Kanoski SE, Rupprecht LE, Fortin SM, et al. The role of nausea in food intake and body weight suppression byperipheral GLP-1 receptor agonists, exendin-4 and liraglutide[J]. Neuropharmacology, 2012, 62: 1916-1927

19. Alhadeff AL, Baird JP, Swick JC, et al. Glucagon-likepeptide-1 receptor signaling in the lateral parabrachial nucleus contributesto the control of food intake and motivation to feed[J]. Neuropsychopharmacology, 2014, 39: $2233-2243$ 